\title{
Poéticas da Oralidade em Mossoró-RN: Memória, dizeres e saberes de poetas populares
}

\section{Poetics of Orality in Mossoró-RN: memory, sayings and knowledge of popular poets}

Ailton Siqueira de Sousa Fonseca ${ }^{1 *}$, Co-autor 1: Jucieude Lucena Evangelista, Co-autora 2 Karlla Christine Araújo Souza, Co-autor 3 Luan Gomes dos Santos de Oliveira²*

\begin{abstract}
RESUMO
Inserida no campo dos estudos culturais das Ciências Sociais, o objeto dessa pesquisa tem como base central a vida e a obra dos poetas repentistas e cordelistas de Mossoró-RN. A escolha dessa cidade teve como prerrogativa as fortes manifestações culturais, artísticas e poéticas desenvolvidas no local, conhecido também como capital da cultura. Nosso objetivo visa apresentar as memórias e paisagens desse lugar por meio dos sujeitos comuns, cordelistas, artistas e artesãos da palavra, do verso escrito e cantado, cidadãos geralmente velhos, portadores de memórias socioculturais, pessoais e poéticas. Sua "arte da palavra" se confronta com a polifonia e fugacidade urbana. Neste texto, colocamos em evidência as vozes de sujeitos societais capazes de revelar outras dimensões da realidade e da cultura, vozes poéticas que evocam memórias não somente de quem fala, mas de um saber que vive sob a camada da cultura de entretenimento e do fugaz consumo da soceidade contemporânea. Com essa pesquisa, conhecemos novos sujeitos, histórias e facetas da realidade da que fazem parte da construção diária da cultura oral e seus saberes.
\end{abstract}

Palavras-chave: Cordelistas; Repentistas; Imaginação Poética; Memória.

\begin{abstract}
Inserted in the field of cultural studies of Social Sciences, the object of this research is based on the life and work of sudden poets and cordelistas from Mossoró-RN. The choice of this city had as its prerogative the strong cultural, artistic and poetic manifestations developed in the place, also known as the capital of culture. Our objective is to present the memories and landscapes of this place through common subjects, cordelistas, artists and artisans of the word, of written and sung verse, generally old citizens, bearers of sociocultural, personal and poetic memories. His "art of the word" confronts polyphony and urban fugacity. In this text, we highlight the voices of societal subjects capable of revealing other dimensions of reality and culture, poetic voices that evoke memories not only of those who speak, but of a knowledge that lives under the layer of entertainment culture and fleeting consumption of contemporary society. With this research, we get to know new subjects, stories and facets of reality that are part of the daily construction of oral culture and its knowledge
\end{abstract}

Keywords: Cordelists; Repentists; Poetic Imagination; Memory.

\footnotetext{
${ }^{1}$ UERN.*E-mails: ailtonsiqueira@uern.br; jucieudelucena@uern.br; karllasouza@uern.br

${ }^{2}$ UFCG. *E-mail: luangomessantos@terra.com.br
} 


\section{INTRODUÇÃO}

O Rio Grande do Norte é considerado um Estado de grandes atribuições no que diz respeito à cultura e à criação de novos artistas. Pensando nessas atribuições a pesquisa teve seu início nos estudos desenvolvidos no Grupo de Pesquisa do Pensamento Complexo (GECOM/UERN) no conjunto de desafios e inquisições cognitvas de nossas temáticas centrais. Ao longo dos anos o grupo realizou várias experiências com atividades que estão ligadas às Ciências Sociais e a cultura da cidade de Mossoró e das suas redondezas. Durante os encontros quinzenais para estudos e discussões no GECOM, tivemos o prazer intelectual de discutir sobre formas alternativas de disseminação da literatura, entre elas a literatura de cordel, a cantoria e o repente. $\mathrm{O}$ gosto em comum por esse tipo de literatura alimentou a criação de ideias e questionamentos acerca da temática das manifestações poéticas populares. Alguns dos participantes já haviam tido experiências com a poética da oralidade e, por isso, alimentou-se, no grupo, a possibilidade de desenvolvermos um projeto que ressaltasse a vida daqueles sábios que mantêm em suas memórias uma verdadeira enciclopédia do improviso e a destreza para criar obras literárias e canções de tão belo encanto que têm o poder de fazer rir, chorar e refletir sobre temáticas diversas.

\section{O CORDEL}

Ao iniciarmos o estudo dessas manifestações poéticas, não se pode deixar de falar sobre os caminhos da literatura de cordel. Tal denominação, já mencionada por Teófelio Braga no século XVII, vem de Portugal e dá-se em virtude dos pequenos folhetos que eram expostos presos a uma corda ou barbante, nos locais onde eram vendidos. Essas "folhas soltas" também chamadas de "folhas volantes", certamente impressas ainda de forma rudimentar, eram normalmente comercializadas nas feiras, nas romarias e nas praças, trazendo narrativas tradicionais como: Imperatriz Porcina, Princesa Magalona, Carlos Magno entre outras. 
O início da literatura de cordel está ligado à divulgação de histórias tradicionais, narrativas de velhas épocas, que a memória popular foi conservando e transmitindo; são os chamados romances ou novelas de cavalaria, de amor, de narrativas de guerras ou viagens ou conquistas marítimas. Mas ao mesmo tempo, ou quase ao mesmo tempo, também começou a aparecer no mesmo tipo de poesia e de apresentação, a descrição de fatos recentes, de acontecimentos sociais que prendiam a atenção da população. Antes que o jornal se espalhasse, a literatura de cordel era a fonte de informação (DIEGUES Jr. 1986, p. 31).

O cordel é considerado poesia oral, pois apesar de ter como característica a forma escrita, essa poesia constitui um texto escrito para ser declamado. Assim, a literatura cordel tem sentido diferente do romance e da poesia erudita, cujo momento de fruição é caracterizado pela experiência individual do leitor com o texto. A experiência estética de leitura do romance e da poesia erudita são marcadas pelo isolamento do sujeito. Por outro lado, a literatura de cordel não é apenas lida, mas os versos são também decorados para serem declamados. Na sua experiência estética a fruição ocorre como momento de experiência compartilhada. O cordel não existe para a introspecção do leitor, mas ganha vida principalmente na habilidade da declamação, na metrificação das sílabas poéticas, na sonoridade rimada e na imaginação coletiva sugerida pela poesia.

Essa condição para a experiência estética da literatura de cordel encontrou nas condições historicamente determinadas do Sertão nordestino, de pouco acesso à educação formal, um fator que foi à leitura coletiva da poesia. Em tempos em que poucas pessoas eram alfabetizadas, nas cidades e nos sítios do sertão, aqueles que sabiam ler se destacavam e eram responsáveis pela leitura e declamação da poesia. Nas feiras, esse momento de leitura coletiva configurava o espetáculo do vendedor de cordéis para chamar atenção dos passantes para as histórias. Nas casas, a leitura coletiva configurava momentos de lazer entre família e vizinhos. O alfabetizado da família ocupava uma posição privilegiada diante dos outros: era o leitor ou o "cantador do cordel", já que a poesia pode ser cantada.

A realidade do universo sociocultural da literatura de cordel já não corresponde a essas condições. A comunidade de ouvintes já não conta como fator típico a falta de letramento dos sujeitos. As formas de publicação, os locais de venda de cordéis e os espaços de leitura coletiva também já não são os mesmos. Antigos cordéis e novas produções podem ser encontrados na forma de livros comercializados em livrarias e bancas de revistas. Hoje a poesia é declamada em escolas, em festas 
populares, em eventos sociais onde o cordelista se apresenta como atração artística, entre outras situações. As cantorias de viola, que hoje também ocupam o universo urbano e que também foram modificadas pelas condições próprias da vida na cidade, possivelmente, é o último contexto tradicional em que se desenvolve a declamação da literatura de cordel.

Esse tipo de poesia é considerado, por muitos, como um "dom”, por outros, apenas facilidades de improvisar palavras em verso. O poeta mossoroense Antônio Francisco consegue descrever um pouco essa arte dizendo:

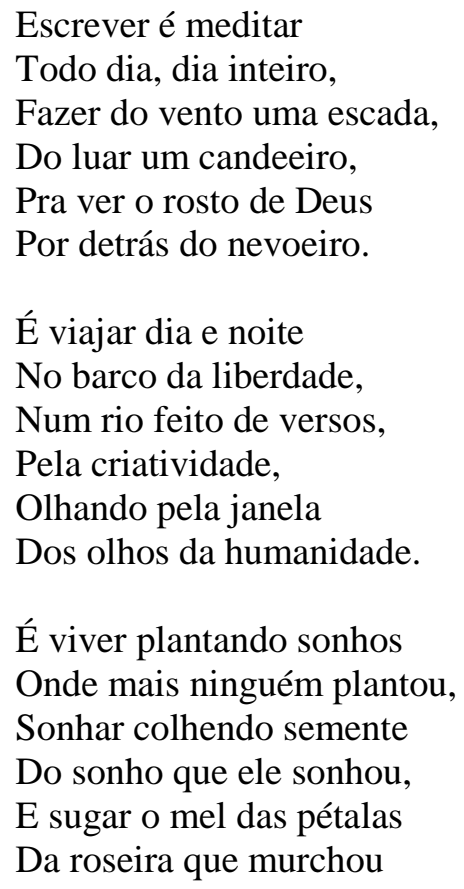

(FRANCISCO Apud FONSECA, 2010, p.123).

Em meados do século XVIII e início do século XIX surgiu uma nova modalidade de apresentação dos cordéis cantados: o apoio musical da viola, também conhecida como "viola de sertanejo", "viola nordestina", "viola cabocla", "viola brasileira" e outras denominações. Esses instrumentos de cordas difundidos no interior do Brasil, símbolo da música popular, também têm ascendência ibérica. Levando a questão para o nível local, mais precisamente em Mossoró, pode-se perceber durante as conversas com os cantadores, que muito da sua produção remete a memórias da infância vividas nos assentamentos rurais da cidade e região. Antônio Nilson da Silva, cordelista e repentista de Mossoró, relatou que a inspiração para produção de suas obras refere-se 
tanto a fatos reais acontecidos na atualidade, na criação de biografias encomendadas, quanto a fatos que marcaram sua infância na zona rural.

O valor da família, da terra e dos animais que conviviam no dia-a-dia desses poetas servem como inspiração para produção de verdadeiros desabafos pessoais e, ao mesmo tempo, como um protesto para com o tipo de qualidade de vida que levam. Percebemos que em grande parte dos cordéis estudados, a imagem do caipira deixava de ser apenas mais um no Cangaço ou Sertão para ser protagonista do que presenciava no campo.

Como podemos perceber até aqui, a trajetória do cordel está intimamente ligada a origem e desenvolvimento da arte do repente. Muitos cordelistas eram, inicialmente, repentistas, ou cantavam seus versos com o acompanhamento da viola.

\section{DE REPENTE, O REPENTE}

O repente é a modalidade de poesia oral nordestina cuja habilidade do improviso se apresenta com suas diversas facetas, narrativas e temporalidades. No espectro da literatura oral nordestina, o repente se distingue do cordel, primeiramente pelo seu caráter de improviso, mas também pelo seu modo de enunciação e de evolução da poesia. O cordelista, ou o declamador de verso, canta a poesia individualmente. O repente é apresentado em dupla. Por essa característica é que o repente é conhecido também como desafio. O improviso em dupla necessita que os cantadores respondam aos versos um ao outro, desse modo fazendo evoluir a cantoria. O improviso também impõe aos cantadores o respeito às regras que compõem a forma poética da cantoria: a metrificação dos versos que caracteriza seu ritmo; a rima, que impõe a sonoridade; a coerência do improviso em relação ao tema e ao lirismo poético, o que se chama de oração.

A comunidade de ouvintes da cantoria também se desenvolveu nas mesmas condições e com as mesmas características da comunidade de ouvintes da literatura de cordel. Com o processo de ocupação de espaços no universo urbano, a cantoria de viola, assim como o cordel, opera mudanças motivadas pelo diálogo com outra cultura. Essas mudanças envolvem principalmente o comportamento e composição da imagem pessoal dos cantadores, além dos conteúdos da poesia. 
No que se refere ao comportamento, os poetas passaram a se apresentar para o ambiente urbano como sujeitos bem informados, versados em atualidades e conhecimentos gerais. No sertão, a imagem do cantador sempre foi a de alguém dotado de um "dom" para fazer poesia e de uma sabedoria traduzida nos versos e rimas. Estes abordavam, em parte, o universo material e simbólico do Sertão, em parte um conhecimento enciclopédico da cultura letrada.

No contexto urbano, essa base de saberes que compõe a poesia não é necessariamente modificada, o que muda é o peso do saber da tradição acumulado e da informação sobre atualidades para a composição da poesia. $\mathrm{O}$ universo sertanejo nunca deixou de ser cantado, pois grande parte do público urbano da cantoria é formado por sertanejos que migraram de pequenas cidades para cidades maiores, mesmo no interior, como é o caso de Mossoró, ou para as capitais do Nordeste e de outras regiões do Brasil. Esse público tradicional é cativo da cantoria por sua relação afetiva com a poesia, pela qual ele mantém laços identitários com o Sertão.

No que diz respeito ao conteúdo da cantoria, as mudanças ocorridas derivam das mudanças na base de composição dos versos. Uma vez que o peso relativo entre os saberes que servem de motivo para a poesia, o conteúdo daquele saber que adquire maior peso, tende a predominar como tema na poética da cantoria.

\section{MATERIAL E MÉTODOS}

Essa pesquisa teve como procedimentos metodológicos básicos a observação direta e a história de vida de cordelistas e repentistas. A observação direta da poesia ocorreu nos espaços do desenvolvimento dessa manifestação poética em Mossoró: nas rodas de cantoria na casa dos cordelistas, nas apresentações em eventos políticos, culturais e educacionais, tais como festivais, feiras comerciais e culturais, eventos escolares etc.

O trabalho possibilitou a observação e o contato direto com a poesia popular e com o auxílio de ferramentas para registro audiovisual e sonoro da poesia e dos ambientes em que ela ocorre, entrevistas com o público presente, nas quais se fez mostrar o perfil dos repentistas e dos cordelistas que ainda se mantém ativos na cultura da cidade de Mossoró. 
As histórias de vida possibilitaram a construção de uma representação do universo do cordel em Mossoró a partir da concepção de seus próprios sujeitos. Por outro lado, o público que o prestigia contribui para essa representação social que eles têm de si mesmos, como percebemos no discurso da dona de casa que colaborou com o desenvolvimento dessa pesquisa, Dona Maria Terezinha da Silva, mais conhecida como "Dona Têquinha", moradora do bairro Abolição II, em Mossoró, que se alegra quando os cantadores se reúnem na esquina da sua rua. Como ela disse: "é muito bonito ver os poetas cantando. Meu filho, Thiago, de oito anos, é que gosta; fica no pé dos homens. Ele me disse que um dia vai ser cantador", confessou Dona Têquinha.

O segundo passo foi o contato com os cordelistas e repentistas da cidade. Foi nessa fase que nos envolvemos com as rodas de cantoria e conversas sobre cordel e ainda fizemos o acompanhamento de manifestações populares. Nessa etapa também pudemos conhecer um pouco da vida e do cotidiano dos poetas mossoroenses, bem como as dificuldades enfrentadas por eles diariamente. Esse envolvimento direto com o universo e os sujeitos da pesquisa nos permitiu duas coisas fundamentais: primeiro, compreendemos melhor as ideias, os hábitos, a matéria prima de algumas das inspirações poéticas dos cordelistas. Segundo, elaboramos com sucesso (mesmo que parcial) um mapeamento dos poetas cordelistas de Mossoró-RN.

O mapeamento ajudou no reconhecimento dos locais onde os poetas residem e se apresentam, bem como o registro de dados e trajetórias desses sujeitos para futuros contatos. Essa atividade foi importante para pesquisa em detrimento das dificuldades encontradas na localização e locomoção que tivemos devido alguns desses poetas residirem em assentamentos rurais com difícil acesso.

Durante os anos da pesquisa, o GECOM juntamente com grupos locais de produção audiovisual, acompanhou e registrou algumas das manifestações desses sujeitos poéticos da cidade. Durante a realização do I Curta Mossoró - projeto idealizado pelo grupo Caminhos, Comunicação \& Cultura, no ano de 2010 - que decidiu homenagear a vida do cordelista mossoroense Antônio Francisco, por meio do documentário de curta metragem, O poeta e a bicicleta. Este é um documentário biográfico sobre esse poeta referenciado nacionalmente por outros poetas. Para os poetas cordelistas de Mossoró, esse evento possibilitou a oportunidade de engrandecer a produção cultural da cidade e valorizar iniciativas como essa de amparar os poetas que 
tem seus trabalhos ocultados nos meios de comunicação. $\mathrm{O}$ curta $O$ poeta e a bicicleta participou de concursos no Brasil e no exterior, sendo bem recebido pelo público.

Em 2011, durante a realização do projeto Mossoró audiovisual, este também realizado pelo Grupo Caminhos, Comunicação \& Cultura, um outro poeta foi homenageado pela produção audiovisual local. Trata-se do documentário $O$ riso e o drama que aborda a vida e a obra do poeta repentista Luiz Campos. Em poucos minutos esse curta conseguiu retratar a importância desse poeta para o cenário cultural da cidade e da região, mostrando, inclusive, como ele é considerado o mestre de vários outros poetas. O curta metragem contou com depoimentos de outros poetas e cordelistas reconhecidos na região, tais como: Gustavo Luz, Antônio Francisco, Rogério Dias e Genildo Costa. A pesquisa acompanhou a produção e exibição desses documentários para, por meio deles, fazer análises de conteúdo e montar a base de dados audiovisual do GECOM, dados que já começam a servir de fontes para outras pesquisas e reflexões intelectuais.

Dentro do cronograma de atividades da pesquisa, também utilizamos entrevistas abertas com os cordelistas de Mossoró e sobre sua produção poética. Os poetas falaram livremente sobre sua trajetória de vida e de construção literária, de suas dificuldades, inspirações, imaginação poética e paisagens que marcam suas vidas e obras. Entre os entrevistados estão Antônio Nilson da Silva, José Antônio da Silva (conhecido, como "Nildo da Pedra Branca"), Valdeci Alves Maniçoba e José Antônio. O diálogo envolveu a passionalidade dos poetas e a fecundidade do mesmo gerou surpresas, repentes, poesias, reflexões entre eles e nós pesquisadores. Foi um momento de reflexão, diálogo e autorreflexão no qual se questionou até mesmo a produção local de cordéis e as dificuldades encontradas pelos poetas locais de ampliação e divulgação de suas obras nessa sociedade marcada pela fugacidade das coisas e das palavras.

Durante o período de entrevistas, conversamos com o poeta cordelista José Antônio. No desenvolver da conversa, foi perguntado sobre sua opinião a respeito do espaço para apresentação de cordelistas e repentistas no cenário de eventos na cidade de Mossoró. De maneira franca, o poeta relatou que falta cachê para poder "bancar" as apresentações. José Antônio completa, na entrevista, dizendo que: "Esse cachê geralmente é concebido para artistas que vem de fora, tomando o espaço dos poetas locais". José Antônio, que teve seu primeiro contato com o cordel aos oito anos de idade por meio da sua avó, Camila Araújo, que comprava o cordel na feira e o lia em casa 
com os familiares. Ele vê no cordel uma paixão pela produção da poesia independente. Apesar da sua experiência como professor da rede estadual e graduando do curso de Direito na Universidade Estadual do Rio Grande do Norte - UERN, ele não consegue se ver longe da criação do cordel, o "seu hobby favorito", como ele mesmo fala. O professor ainda estimula seus alunos à leitura e confecção do cordel, por assim acreditar que esse estilo de literatura possa agir como auxílio para novos leitores.

A Feira do Livro de Mossoró, que acontece anualmente e reúne editores, editoras, escritores e intelectuais de vários lugares do Brasil, em 2011 já contou com um espaço para comercialização e divulgação de trabalhos de cordéis ou com referência ao mesmo. O espaço também dá oportunidade para novos cordelistas que desejam apresentar seus trabalhos, dentre eles uma garota de 13 anos de idade, Monique Stefhany Silva Ferreira, chama a atenção pelo gosto à literatura e criação de cordéis. Ao entrevistá-la, Stefhany disse que escreve cordel desde 2008: "na escola que estudo as professoras me apresentaram o cordel, daí eu gostei e comecei a escrever”. Quando cursava o $7^{\mathrm{a}}$ ano da escola, essa jovem cordelista foi ganhadora do Prêmio Cosern de Literatura de Cordel na categoria "Fundamental", com o cordel A importância que tem o meu Livro. Abaixo um pequeno fragmento da última publicação da jovem poeta:

\author{
Deus me ajudando escrevo \\ Respeito à diversidade \\ Satisfeita me inspiro \\ Com toda felicidade \\ Para falar de culturas \\ Com minha capacidade. \\ Saiba como respeitar \\ Um amigo, um parceiro. \\ Nunca, jamais maltratar. \\ O nosso bom companheiro \\ Amar, cuidar, respeitar. \\ O nosso melhor parceiro. \\ (FERREIRA, 2010b, p. 01).
}

Nem sempre os poetas populares têm o devido respeito que merecem, e por isso, são subjugados por pessoas ou entidades leigas durante a execução das manifestações em público. Foi o caso ocorrido no dia 13 de março de 2011, na feira livre da "COBAL", em Mossoró, onde os representantes do grupo "POEMA" foram expulsos do local após uma apresentação. Entre os componentes do grupo estava o 
poeta Caio César Muniz, que revelou sua indignação a respeito do ocorrido na entrevista cedida ao Jornal O Mossoroense, do dia 27 de março de 2011. "Quando começamos esta grande brincadeira - que agora virou coisa séria - chamada POEMA, as ruas eram o nosso palco, as praças a nossa sala de recitais, os bares nosso aconchego noturno para troca de versos.”. Porém o cordelista acrescenta que nem sempre as apresentações são bem aceitas, pois sempre existiram olhares de reprovação acerca da iniciativa dos poetas. E mais: "não somos marginais, nunca fomos. Somos artistas e a única coisa que pedimos é um pouco menos de dureza nos corações", completou Caio em entrevista ao jornal. A opinião sobre o que pensam as pessoas sobre o trabalho organizado pelos cordelistas desse projeto parece ser bem realista e, por isso, fazem deles bons receptores de críticas. O poeta termina dizendo "a nossa poesia, a nossa arte, precisa agora, mais do que em qualquer outro tempo, de que a defendamos em todos os lugares".

Mossoró ainda conta com um calendário de eventos que exalta tanto a cultura popular quanto os eventos religiosos e comerciais da cidade. Festa de Santa Luzia, Alto da Liberdade, Feira do livro de Mossoró, Mossoró Mix, Feira do Bode e as Vaquejadas. Esses são alguns dos exemplos dos eventos promovidos na cidade. Dentro desse calendário, no mês de junho, na programação dos festejos do Mossoró Cidade Junina, acontece o Festival de Repentistas do Nordeste que, no ano de 2011, chegou a sua $11^{\mathrm{a}}$ edição. Em uma conversa com Aldaci de França, coordenador do evento, o mesmo relatou que o festival é uma forma de propagar ainda mais a cantoria e abrir as portas do mercado para esses cantadores, que tem seu trabalho divulgado no cenário nacional. O festival contou com a participação especial dos poetas repentistas José Ribamar e Antônio Francisco, ambos de Mossoró. Ribamar relatou sua satisfação em participar de um evento tão grandioso no qual seus colegas repentistas estão participando, só lamenta a pouca representação de poetas da cidade no evento. Ribamar ainda disse durante a entrevista que "a cidade de Mossoró precisa ampliar a produção de eventos como esse. Falta incentivo da iniciativa pública e privada para apresentações em outros espaços", completa o poeta repentista. O concurso contou com a participação de repentistas dos estados de Pernambuco, Paraíba, Ceará, além do Rio Grande do Norte.

\section{RESULTADOS E DISCUSSÃO}


Durante o desenvolvimento das atividades do projeto, conseguimos alguns dados que irão ajudar na continuidade de pesquisas futuras e ainda aperfeiçoar a já existente.

A convivência com os poetas nos levou a tentar criar um perfil do poeta mossoroense, assim, obtendo um melhor resultado do pensamento individual e em grupo da produção de cordel na cidade. Pensando nesta proposta, foi realizada entrevista com os cordelistas que aceitaram responder algumas perguntas acerca da sua vida e da sua carreira. Lembrando que por se tratar de uma pesquisa de opinião, a identidade dos participantes não foi identificada no momento do preenchimento. A pesquisa contou com 16 perguntas que eram ligadas desde a faixa etária e escolaridade até o ponto de vista individual sobre as transformações que essa literatura vem causando na sociedade. No total foram nove pessoas que aceitaram responder o questionário. Depois da realização da pesquisa, seguimos para a segunda fase que consiste na interpretação dos dados.

Pudemos perceber que o percentual de mulheres que participam da atividade é mínimo, tendo em vista a proporção referente a dos homens. Esse fato faz o público feminino ser pouco criador na promoção e confecção do cordel na cidade. A atividade do cordel ainda é mais voltada para o público masculino, se considerarmos a produção de cada um que participou da pesquisa. Constatamos que o grau de escolaridade dos poetas é considerado baixo, devido à maioria apenas contar com o ensino fundamental incompleto que, de certa forma, surpreende graças aos saberes que esses poetas carregam em suas memórias. A justificativa, talvez seja que boa parte dos entrevistados não tiveram ou não puderam ter a oportunidade de dar continuidade aos estudos, devido a trabalhos dentro do convívio familiar na zona rural.

Foi analisado o percentual de cordelistas que participaram de concursos de cordéis ou premiações na área da literatura independente. A percentagem mostra que apenas $43 \%$ dos participantes já tiveram a oportunidade de estar presente em competições com cordel. Hoje, no Rio Grande do Norte já existe um calendário de eventos e concursos envolvendo a arte do cordel, entre eles o Prêmio COSERN e o Prêmio Fomento, que todos os anos realizam concursos para a disseminação e a promoção da cultura do cordel. 


\section{CONCLUSÃO}

De acordo com o desenvolvimento da pesquisa foi constatado que os poetas populares sentem carência de apoio financeiro e moral para continuar desenvolvendo suas habilidades com a poesia, apesar de muitas vezes, algumas dificuldades serem a matriz de sua poesia. Outras dificuldades também foram relatadas pelos artistas da palavra, principalmente aquelas dificuldades relacionadas à infância difícil que gerou consequências no presente como, por exemplo, a falta de estudo.

Hoje, o público feminino que está envolvido no desenvolvimento do cordel e a cantoria ainda é pouco conhecido no cenário local e, por isso, sendo pouco divulgado para os apreciadores da poesia. Mesmo que existam aqueles que desprezam ou não respeitam esse tipo de cultura, existem também aqueles que presam pela consagração de formas alternativas e inteligentes de se fazer cultura. A prova disso foi à força de vontade de alunos de graduação e projetos afins que desejam registrar e mostrar para população o que se produz na cidade.

Estamos dando continuidade à pesquisa com grande expectativa de alavancar novos conhecimentos da vida e obra de cordelistas e repentistas de Mossoró. Seguiremos essa etapa participando quinzenalmente das reuniões do Grupo de Pesquisa do Pensamento Complexo - GECOM - para leituras e discussões teóricas. Retornaremos o contato com os cordelistas e repentistas para conhecer e registrar suas poesias e seus desafios cotidianos. Usaremos o acervo de dados do GECOM para sistematização dos dados coletados até hoje, de modo a criar um comparativo de mudanças ocorridas durante todo o período de pesquisa. Nossa alegria é saber que esse tipo de iniciativa pode ajudar na construção identitária e memorialística dos poetas nordestinos que um dia sonham ter seus trabalhos valorizados pela sociedade.

\section{REFERÊNCIAS}

ABREU, Márcia. Historia de cordéis e folhetos. Campinas, SP: Mercado de letras: Associação deleituras do Brasil, 1999. (Coleção Historias de Leituras).

CAMPOS, Lindoaldo. ABC da poesia-inspirartividades com palavras. Natal (RN): Sebo Vermelho,2010. 279 p. (Coleção João Nicodemos de Lima, v.297).

DIEGUES, Jr. (et al). Literatura popular em versos: estudos. Belo Horizonte, Itatiaia, São Paulo: Editora Universidade de São Paulo; Rio de Janeiro: fundação Casa Rui Barbosa, 198686 p. 
MORIN, Edgar. Amor, poesia, sabedoria. 9 ed. Rio de Janeiro: Bertrand Brasil, 70p. 2010 .

FERREIRA, Monique Stefhany Silva Ferreira. Respeito à diversidade. Mossoró: Queima-Bucha, 2011.

FONSECA, Ailton Siqueira de Sousa. Sabedorias do instante: algumas considerações sobre o repente e a literatura de cordel. In: SILVA, Anaxuell Fernando, SANTOS, Anderson Cristopher (org) Ciência: humana e Potiguar. Natal: Programa de Pós Graduação em Ciências Sociais da UFRN, 2010. p. 109-137.

LOPES, José Rogério, SILVA, André Luiz. Os lugares da viola no vale do Paraíba (SP). Sociedade e Cultura. v. 11, n.2, p.183-190, 2008.

MUNIZ, Caio Cesar. Respeito à poesia. Mossoró: Jornal O Mossoroense, 27 de março de 2011.

\section{Recebido em: 15/09/2021}

Aprovado em: 30/09/2021

Publicado em: 08/10/2021 